\title{
Ensuring Textbook Quality through Evaluation: An Issue in Pakistan
}

\author{
Khalid Mahmood ${ }^{1}$, Muhammad Saeed ${ }^{2}$ \\ ${ }^{1}$ Canada-Pakistan Basic Education Project, Lahore, Pakistan \\ ${ }^{2}$ Institute of Education and Research, University of the Punjab, Pakistan
}

\begin{abstract}
Role of textbook in any education system can not be ignored. Quality of textbook has always been a major cause concern in any country. Like many other countries, in Pakistan, textbook evaluation is being done through a regulatory body at Federal level, called Curriculum Wing (CW), Ministry of Education. CW approves textbooks after necessary review and evaluation. This study explores, to what extent the approved books have harmony among them with respect to basic characteristics of textbook and how qualification, experience and nature of job in education department affect the evaluation. Eight textbooks, four in each of the two subjects (science and mathematics) introduced in the public and private sector schools of the country were selected for the study. Data was collected through a questionnaire called 'Textbook Evaluation Form' from 230 teachers and 67 teacher educators. Analysis of data reveals that there is discord among the textbooks and the evaluation of textbooks is influenced by qualification and experience on some characteristics of textbooks.
\end{abstract}

\section{Introduction}

Pakistan is a developing country of South East Asia. It appeared on the world globe on $14^{\text {th }}$ of August, 1947 as an independent sovereign state. It covers an area of approximately 779,000 sq.km with an estimated population of 180 million. It has five provinces: Baluchistan, Gilgat Baltistan, Pakhtoon Khawa, Punjab, and Sindh; the Federal Capital of Islamabad; Federally Tribal Administrative Areas (FATA); and Azad Jammu \& Kashmir (AJK). Pakistan has a very low literacy rate of about $57 \%$. The teachers possessing higher secondary schooling (12 years) or first degree along with one year professional training teach in elementary schools, while to become a secondary school teacher, one must either possess bachelor or master degree in the relevant subject along with one year professional training usually BEd. At school level, annual system of examination prevails with some focus on continuous assessment but at higher level both annual and semester system can be seen. In Pakistan threetier educational structure i.e. 8 years elementary, 4 years secondary and 2-6 years tertiary or higher education, is followed. The school curriculum development is the purview of the Curriculum Wing (CW), Ministry of Education at federal level and is undertaken through a consultative process with the provincial governments through their respective education departments. In order to implement the curriculum, textbooks are developed by the respective province through private and public sector publishers.

A textbook is an organized body of material useful for the formal study of a subject area. The development and maintenance of a useful textbook can be an open and collaborative process. School textbooks pass on fundamental knowledge to the younger generation. "Textbooks certainly provide an important tool in transferring knowledge"[1]. This transfer of knowledge is not limited to merely conveying the information about a subject, but also aims at developing the understanding of the subject. "In the absence of any other widely available sources of information, the textbook also becomes the most important and often the only source of content and pedagogic information for the teacher" [2]. Textbooks are necessary to teach concepts and content and inculcate skills required by the curriculum.

Textbooks are at the heart of educational enterprise, as they offer students "a rich array of new and potentially interesting facts, and open the door to a world of fantastic experience" [3]. Textbooks are the primary vehicles for delivering content knowledge, for determining in large measure what goes on in a class, and for assessing what students do and do not learn. It has been identified that access to and availability of textbooks is a particularly significant factor in predicting academic achievement [4].

In most of the countries textbooks are written by experts with the assistance of publishers and these textbooks are evaluated by a government agency. In Pakistan, role of textbook development rests with the provincial or regional Textbook Boards, and private publishers. These boards and private publishers try to publish the textbooks according to the guidelines 
provided in the national curriculum, approved by the CW, Ministry of Education. The role of textbook evaluation performed by the Curriculum Wing is to ensure that textbooks are according to the curriculum guidelines. "In Pakistan, the textbooks are supposed to occupy a central position in the process of teaching and learning to the extent that assessment system and classroom teaching seem to revolve around the textbooks"[5].

It is generally perceived by the educationists; teachers and parents that in Pakistan textbooks are still not compatible with the textbooks used in the developed countries of the world [6]. Due importance has not been given to the development and evaluation of textbooks inspite of their paramount importance in the education system [7, 8]. Textbooks have been used for decades without piloting and formal investigation and research as to their usefulness and desirability of being depended upon [9, 10].

The methods of textbook research have evolved so as to meet the needs of different analytical purposes: these include identifying the obvious content coverage, didactical approaches or uncovering the hidden curriculum, the underlying assumptions and the connotations which a text may evoke in the student's mind [11]. This study addresses the following core question:

To what extent are the textbook evaluation criteria used by the Ministry of Education, Pakistan congruent with the (normatively desirable) internationally recognized criteria for the approval/selection of quality textbooks?

\section{Methodology}

\subsection{Sample Selection}

For the study, Primary School Teachers, and Teacher Educators / Subject Specialists were selected. Stratified Random Sampling Technique was used to draw the sample of the study from the teacher education institutions of Punjab province and the capital territory of Islamabad. One hundred and twenty (120) Potential Teacher Educators / Subject Specialists were included in this sample. All Teacher Educators and Subject Specialists were drawn from Punjab province and Islamabad for two reasons: a) About three-fourth of the experts in Pakistan included in the sample of the study were from these two regions so comparison of the results from the two data sets could be appropriate; and b) Punjab comprises about $57 \%$ of the total population of the country. The province was further divided into two major categories with respect to state of development. Lahore was selected from developed regions as it is the largest city of the Punjab and the most developed in the regions. Muzaffar Garh was selected from less developed regions as it represents the remote areas of the Punjab. 120 Teacher Educators/ Subject Specialists were drawn from these three districts. The district-wise sample breakup was: Lahore $(30 \mathrm{M}+30 \mathrm{~F})$ and Muzaffar Garh (20M+20F), and Islamabad $(10 \mathrm{M}+10 \mathrm{~F})$. The second category of the sample included 240 Primary School Teachers from the same three districts and the district-wise sample breakup was: Lahore $(70 \mathrm{M}+70 \mathrm{~F})$, Muzaffar Garh (40M+40F), and Islamabad (10M+10F).

Out of the sampled participants 67 (55.8\%) teacher educators/subject specialists and 230 (95.8\%) teachers responded to the questionnaire. It shows that teachers' participation in the study was almost according to the plan. However, in the case of teacher educators, the response rate was a bit low. One of the reasons of this low response was non-availability of teacher educators for participating in the workshops due to their other commitments.

\subsection{Instrumentation}

A Textbook Evaluation Form was developed by the researchers to find judgment of teachers, teacher educators and subject specialists on the approved textbooks was based on various characteristics of a textbook to describe the review, evaluation and approval of textbooks by the Ministry of Education. The instrument was a five point rating scale based on general characteristics of the textbooks. The instrument addressed following key characteristics of textbook drawn through relevant literature review.

i. Conformity to curriculum policy and scope; it refers to statements included in the form about coverage of the contents and objectives of the National Curriculum, and ideology of the nation.

ii. Vocabulary and format; for this characteristics, statements regarding level of the vocabulary used in the textbook, page layout, relevance of the pictures and illustrations, print style and size, readability of the content etc., were included in the form.

iii. Learning and assessment; it refers to nature and relevance of learning activities included in the book, alignment of the objectives of the National Curriculum, activities, and assessments exercises at the end of each chapter.

iv. Horizontal and vertical alignment; it refers to statements included in the form regarding logical links in the content presented within and among the chapters/units, content organization and presentation, etc. 
v. Acceptability; for this characteristic statements about students' divers environment and background, were included.

The research instrument was developed in two languages i.e. Urdu and English to make it user friendly. In order to bring more clarity into the national language version, English text of the statements was also given.

Grade 3 textbooks for the subjects of science and mathematics of each publisher were selected as this level is the middle stage of primary classes and it gives more room for exploring horizontal and vertical links of the book. The study was delimited to four publishers (two public and two private). In this way total eight textbooks were analyzed for the study.

The validity of the questionnaire was ensured through experts' opinion. Cronbach Alpha was applied to the questionnaire so as to ensure its reliability. The reliability of the final questionnaire was established at 0.938 . One of the most possible reasons for high Alpha value was the improvement made in the instrument after its piloting. Factors-wise reliability of the items included in the questionnaire was also calculated and it was more than 0.7 for each of the five factors that show even distribution of the number of statements narrated for the different factors of textbooks Scales with the Alpha value are considered reliable. The Alpha value also reflects that the form was quite clear to all respondents and people understood what had been said in these statements $[12,13]$. There were two major reasons for effectiveness of the form; a) it was bilingual, that is, both in Urdu and English languages, and b) clarification of the terms used in it was provided, when and where needed by the participants.

The data was collected in workshop setting. Approved textbooks of the sampled publishers were provided to the respondents in these workshops. Both teachers and teacher educators were requested to pick an approved textbook for filling up the questionnaire.

\section{Data Analysis}

Through calculating Standard Deviations of all the factors it was observed that majority of respondents views were similar to each other except 'Vocabulary and Format' factor. In order to interpret the data; item-wise mean score for each of the above mentioned factors was calculated. The Mean Score was interpreted on the scale, shown in Figure 1.

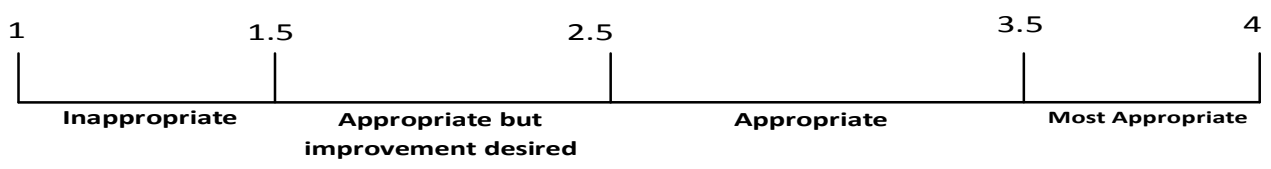

Figure 1. Scale for interpretation of mean score

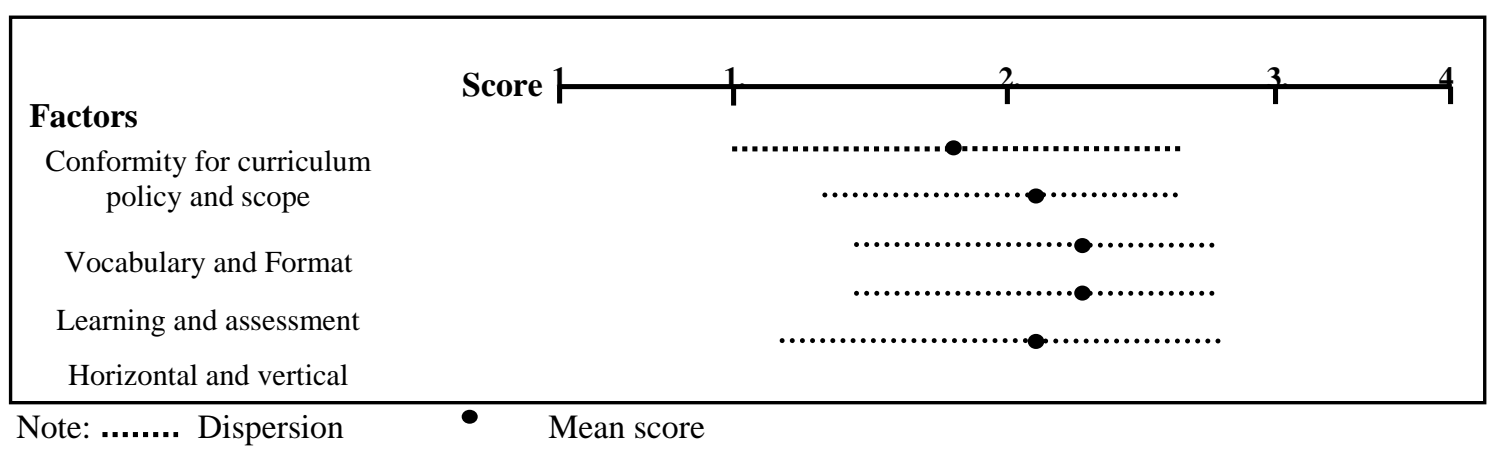

Figure 2. Factor-wise mean score assigned by teachers, teacher educators and subject specialists to various factors of approved textbooks along with dispersion in their judgments

Figure 2 shows the characteristic-wise mean score and standard deviation. It depicts that majority of the respondents thought that the approved textbooks were 'appropriate' except 'Conformity for curriculum policy and scope’; mean score of this factor was lying at 2.3. The dispersion in the judgments was also not so wide. However, the characteristics of 'vocabulary and format' and 'acceptability' were almost lying at the mean score of 2.6. Similarly, in case of the characteristics of 'learning and assessment' and 'horizontal and vertical alignment of the text', mean 
score were lying somewhere at 2.8. Different studies around the world have studies the same phenomenon.

Riazi and Mosallanejad [14] studied the types of learning objectives in four textbooks used in Iran. In terms of level of difficulty and text length, a logical sequence of difficulty was noticed in the textbooks. Moreover, the researchers conclude that the most prevalent learning objectives in the textbooks were lower-order cognitive skills, that is, knowledge, comprehension, and application.
Majority of the respondents' judgments were overlapping. This also reflected that there was consistency in thinking and responding about various characteristics of the approved textbooks. In order to further probe into the difference between the judgments of teachers and teacher educators/subject specialists on the various characteristics, F-ratio of each characteristics was calculated, which can be seen in Table 1.

Table 1. One Way Analysis of Variance Summary of Teachers and Teacher Educators Judgment on Different Characteristics of Textbooks (with respect to their designation)

\begin{tabular}{|l|l|r|r|r|r|}
\hline \multicolumn{1}{|c|}{ Factor } & & \multicolumn{1}{c|}{ df } & $\begin{array}{c}\text { Sum of } \\
\text { Squares }\end{array}$ & $\begin{array}{c}\text { Mean } \\
\text { Square }\end{array}$ & \multicolumn{1}{c|}{ F } \\
\hline \multirow{2}{*}{$\begin{array}{l}\text { Conformity for curriculum } \\
\text { policy and scope }\end{array}$} & Between Groups & 2 & 34.330 & 17.165 & 2.307 \\
\cline { 2 - 6 } & Within Groups & 253 & 1882.529 & 7.441 & \\
\hline Vocabulary and Format & Between Groups & 2 & 116.027 & 58.013 & $3.453^{*}$ \\
\cline { 2 - 6 } & Within Groups & 260 & 4368.559 & 16.802 & \\
\hline \multirow{2}{*}{ Learning and Assessment } & Between Groups & 2 & 11.622 & 5.811 & 0.686 \\
\cline { 2 - 6 } & Within Groups & 246 & 2083.847 & 8.471 & \\
\hline \multirow{2}{*}{$\begin{array}{l}\text { Horizontal and vertical } \\
\text { alignment of the text }\end{array}$} & Between Groups & 2 & 15.193 & 7.596 & 0.912 \\
\cline { 2 - 6 } & Within Groups & 248 & 2065.444 & 8.328 & \\
\hline Acceptability & Between Groups & 2 & 15.333 & 7.666 & 1.349 \\
\cline { 2 - 6 } & Within Groups & 259 & 1471.618 & 5.682 & \\
\hline
\end{tabular}

Table 1 reveals that there was no significance difference in the judgments of teachers and teacher educator on all characteristics except, 'Vocabulary and Format' at 0.05 levels of significance. There might be several reasons for that, however, one possible reason might be that, this characteristics of textbook was easy to explore as compared to others. Vocabulary given in the textbooks was not according to the standards suggested in the literature for a particular grade and level. Literature suggests two steps down vocabulary from the grade for which the book has been developed for other than language textbooks [15, 16]. Educational research has proven strong relationship between vocabulary knowledge and reading comprehension [17]. Vocabulary experts agree that adequate reading comprehension depends on a person already knowing between 90 and 95 percent of the words in a text. Teachers who were the frequent users of these books understood this characteristic better as compared to the teacher educators/subject specialists.

For further analysis, the researchers further looked into the data and calculated F-ratio with respect to the professional qualifications of the

Table 2. One Way Analysis of Variance of Teachers and Teacher Educators Judgment on Different Characteristics of Textbooks (with respect to their professional qualification)

\begin{tabular}{|c|c|c|c|c|c|}
\hline Factor & & df & $\begin{array}{c}\text { Sum of } \\
\text { Squares }\end{array}$ & $\begin{array}{c}\text { Mean } \\
\text { Square } \\
\end{array}$ & $\mathbf{F}$ \\
\hline \multirow{2}{*}{$\begin{array}{l}\text { Conformity for curriculum policy and } \\
\text { scope }\end{array}$} & Between Groups & 3 & 62.434 & 20.811 & $2.802 *$ \\
\hline & Within Groups & 275 & 2042.219 & 7.426 & \\
\hline \multirow[t]{2}{*}{ Vocabulary and Format } & Between Groups & 3 & 26.230 & 8.743 & 0.49 \\
\hline & Within Groups & 283 & 5051.714 & 17.851 & \\
\hline \multirow[t]{2}{*}{ Learning and Assessment } & Between Groups & 3 & 20.611 & 6.870 & 0.824 \\
\hline & Within Groups & 268 & 2233.609 & 8.334 & \\
\hline \multirow{2}{*}{$\begin{array}{l}\text { Horizontal and vertical alignment of } \\
\text { the text }\end{array}$} & Between Groups & 3 & 54.488 & 18.163 & 2.236 \\
\hline & Within Groups & 270 & 2193.454 & 8.124 & \\
\hline
\end{tabular}


respondents.

Table 2 indicates that professional qualification of the respondents' variable did not have significant effect on their judgments on the approved textbooks except 'Conformity for curriculum policy and scope'. It shows consistency in thinking of teachers and teacher educators regarding the four factors vocabulary and format, learning and assessment, horizontal and vertical alignment of text, and acceptability. This might be due to the reason that all teacher educators have similar qualifications. The highest consistency, in other words, least difference, in the perceptions of the respondents was observed in the characteristics of 'vocabulary and format' (Fvalue 0.49) and 'learning and assessment' (F-value 0.824). The remaining two factors i.e. 'horizontal and vertical alignment of the text' and 'acceptability' were lying somewhere in the middle, as can be seen in Table 2.

In order to see which characteristic was affected by qualification of the respondent, Post Hoc Tests for multiple comparisons was used, as can be seen in Table 3.

Table 3. Post Hoc Value for Judgments of Teachers and Teacher Educators on Various Characteristics of Textbooks

\begin{tabular}{|c|c|c|c|c|c|c|c|}
\hline \multirow[t]{2}{*}{$\begin{array}{c}\text { Key characteristics } \\
\text { of textbook }\end{array}$} & \multicolumn{2}{|c|}{$\begin{array}{c}\text { Certificate } \\
\text { (PTC, CT, OT) } \\
(1)\end{array}$} & \multicolumn{2}{|c|}{$\begin{array}{l}\text { B. Ed. } \\
\text { (2) }\end{array}$} & \multicolumn{2}{|c|}{$\begin{array}{c}\text { Post Graduate } \\
\text { (M.Ed., M. Phil) } \\
\text { (3) }\end{array}$} & \multirow[t]{2}{*}{$\begin{array}{l}\text { Post } \\
\text { Hoc }\end{array}$} \\
\hline & Mean & SD & Mean & SD & Mean & SD & \\
\hline $\begin{array}{l}\text { a) Conformity for } \\
\text { curriculum policy } \\
\text { and scope }\end{array}$ & 6.27 & 2.401 & 6.46 & 2.436 & 6.50 & 1.195 & $1<2,3$ \\
\hline $\begin{array}{l}\text { b) Vocabulary and } \\
\text { format }\end{array}$ & 12.32 & 3.647 & 14.43 & 3.390 & 13.50 & 3.000 & $1<2,3$ \\
\hline $\begin{array}{l}\text { c) Learning and } \\
\text { assessment }\end{array}$ & 9.24 & 2.634 & 9.69 & 2.983 & 9.00 & 1.414 & $3<1,2$ \\
\hline $\begin{array}{l}\text { d) Horizontal and } \\
\text { vertical alignment } \\
\text { of the text }\end{array}$ & 9.20 & 2.676 & 8.69 & 1.750 & 9.75 & 2.217 & $3<1,2$ \\
\hline e)Acceptability & 5.75 & 2.009 & 6.79 & 1.888 & 6.25 & 2.75 & $1<2,3$ \\
\hline
\end{tabular}

Table 3 informs that professional qualifications have impact on the judgments at large. The group with B.Ed. qualification seemed consistence in their judgments regarding all characteristics of the approved textbooks, except the aspect of 'vocabulary and format'. However, group with lowest qualifications (PTC/CT/OT) had more positive judgments on 'learning and assessment' and 'horizontal and vertical alignment of the text'. They were critical for the rest of the characteristics. The group with highest qualification had different opinion as compared to the group with lowest professional qualification.

Statement-wise mean score was calculated and presented in table 4, to ascertain the implementation of the criterion used by the Ministry of Education to review the textbooks.

Table 4 depicts that female respondents were more positive in making judgments on various characteristics of the approved textbooks. No mean score against any statement was less than 2.5. So, according to the female respondents all the approved textbooks were appropriate according to the characteristics mentioned in the Evaluation Form. This implies that all the textbooks went through a uniform procedure of review and evaluation. However, as compared to their female counter parts, male respondents had their reservations about the approved textbook. According to their judgment more than $50 \%$ of the characteristics of the approved textbooks gained mean score less than 2.5 , so male respondents were more critical about these aspects as majority of the teachers thought that 'improvement is desired'. Those characteristics with less than 2.5 mean score (according to mean score low to high) are as follow. 
Table 4. Gender -wise Mean Score Assigned by the Respondent to Characteristics of Textbooks

\begin{tabular}{|c|c|c|c|c|}
\hline \multirow{2}{*}{ Statement } & \multicolumn{2}{|c|}{ Male } & \multicolumn{2}{|c|}{ Female } \\
\hline & $\mathrm{N}$ & Mean & $\mathrm{N}$ & Mean \\
\hline 1. Appearance of Title Page & 158 & 2.70 & 134 & 2.89 \\
\hline 2. Durability of cover/binding & 155 & 2.36 & 134 & 2.58 \\
\hline 3. Correspondence between size of print and age and grade of students & 157 & 2.43 & 134 & 2.85 \\
\hline 4. Correspondence between style of print, age and grade of students & 158 & 2.43 & 132 & 2.80 \\
\hline 5. Page Layout & 158 & 2.66 & 133 & 2.87 \\
\hline 6. Relevance of pictures, tables, figures and graphs with text & 156 & 2.66 & 133 & 3.12 \\
\hline 7. Connection to diverse environment & 158 & 2.47 & 132 & 2.95 \\
\hline 8. Connection to diverse student background & 157 & 2.39 & 132 & 2.68 \\
\hline 9. Readability according to student's level & 158 & 2.37 & 134 & 2.84 \\
\hline 10. Explanation of the content matter within the student's vocabulary & 158 & 2.39 & 133 & 2.66 \\
\hline 11. Logical links in the contents & 158 & 2.69 & 132 & 2.78 \\
\hline 12. End of chapter assessments & 156 & 2.70 & 133 & 2.76 \\
\hline 13. Activities and their relevance to contents & 154 & 2.51 & 129 & 2.88 \\
\hline 14. Content Accuracy & 157 & 2.61 & 129 & 2.93 \\
\hline 15. Content organization and presentation & 155 & 2.64 & 126 & 2.78 \\
\hline 16. Content matching with student intellectual level & 156 & 2.47 & 133 & 2.75 \\
\hline 17. Content is helpful in developing thinking skills in the students & 157 & 2.46 & 130 & 2.88 \\
\hline 18. Reflection of ideology of Pakistan in the content & 155 & 2.19 & 128 & 2.52 \\
\hline 19. Alignment of the content with national curriculum objectives & 156 & 2.37 & 131 & 2.63 \\
\hline 20. Covers scope of the content of the national curriculum & 156 & 2.56 & 128 & 2.70 \\
\hline
\end{tabular}

- Reflection of ideology of Pakistan in the content

- Durability of cover/binding

- $\quad$ Readability according to student's level

- Alignment of the content with national curriculum objectives

- $\quad$ Connection to diverse student background

- Explanation of the content matter within the student's vocabulary

- $\quad$ Correspondence between size of print and age and grade of students

- $\quad$ Correspondence between style of print and age and grade of students

- Content is helpful in developing thinking skills in the students

- $\quad$ Connection to diverse environment
- Content matching with student intellectual level

This analysis indicates that approved textbooks are lacking on the above-mentioned characteristics. This implies that during the review of the textbooks the criteria were not explicit to all members of National Textbook Review Committee (NTRC).

The suggestions offered by the respondents on the Evaluation Form are analyzed below.

\section{i. Alignment between the objectives and text}

One of the basic qualities of a good textbook is that its objectives should be aligned with the contents and activities given in the national curriculum. Most of the respondents who evaluated the textbooks did not show satisfaction in this regard. One of the 
respondents commented on mathematics textbook for grade 4 students;

The objectives given in the national curriculum of mathematics are not fully covered in this book. The curriculum demands higher order think and problem solving. But the book in my hand does not contain exercises for the students that require problem solving skills.

Our analysis suggests that the teachers' limited understanding of the scientific concepts and limited pedagogical content knowledge did not allow them to make sense of the relating objectives laid down in the curriculum and information or activities provided in the textbook. Another respondent commented on science textbook for grade 3 students;

One of the objectives of science at primary level is to promote application of scientific knowledge in familiar and unfamiliar situations and in daily life including those of personal, social and environmental nature. However, the text of the book in hand does not promote this skill in students. Most of the activities given in the textbook are not aligned with contents of the book. The [publisher] should be asked for inclusion of the daily life examples that also encourage the use of technology as we are living in the age of technology

ii. Assessment: A number of the respondents pointed out that the textbooks lack in assessment exercises at the end of each chapter. One of the respondent commented as;

The content of this book [grade 3 English] does not match with the end of lesson [chapter] assessments according to level of students of the grade 3. Some exercises are above the mental level of the students. There is a need to improve end of chapter assessments.

For mathematics textbook, a respondent recommended as;

There is a need to improve sequencing of the end of chapter assessments especially in mathematics books. There should be easy examples and end of chapter assessments to promote students' ability. These should be in line with examination system. For class 1 question should be short and of such kind that students could find their answer

Other responses were grouped as; short answer questions should be included that would develop critical thinking in the students; objective type questions should be given more importance in the end of chapter assessments. Some of the participants also recommended that number of essay type questions should be increased along with objective type questions to create trend of writing and learning. The questions of the exercises should assess the actual learning in context to content and activities given in the textbook.

iii. Format and Vocabulary: Majority of the respondents offer their suggestions about the format and vocabulary of the approved textbooks. One of the respondents suggested;

In my opinion this book [grade 3 science] helps in enhancing the knowledge of the students. It helps student to know more about information about science subject in the age of the science. However, the English terminology used in this book hinders the learning of the students. There is need to use Urdu vocabulary for this terminology. This will help students in increasing their understanding of the subject.

Another respondent asserted that; The vocabulary used in this book [grade 3 mathematics] is difficult for the students of grade 3. There are number of words that have been used in this book but have not been learnt by the students. The word given in English should also have their Urdu translation in the book.

The other suggestions given by the respondent are grouped as;

- Vocabulary should be according to the students' mental level and text should be in the national language. There should be glossary of new and difficult words in the book. Include activities to promote creative thinking.

- Present the content in a logical sequence (easy to difficult). There should be 
illustration to perform the activities given in the book. There is a need to make the title more attractive. More colored pictures that are aligned with the content matter should be used.

- Size and style of the font should be according to grade and level of the students. Give more illustrations to explain the content. Improve page layout (give some space between pictures and content). Keeping in view the age of the students in primary classes, there is a need to improve paper quality as pages of these books tire out very soon.

iii. Curriculum Philosophy: Majority of respondent suggested that ideology of Pakistan should be promoted through textbooks and examples from local context should be included. One of respondent, for example, stated that;

Our textbooks should give examples from our local context. But the book in my hand [grade 3 science] almost blinds from this perspective. I know it is science book. It should promote scientific concepts, but we could talk about our context and how could we apply the learning from this subject in our context.

Some of the important other recommendations made by the respondents in this regard were:

- More content to highlight the Ideology of Pakistan and to promote Islamic ideology

- Promotion of local culture through inclusion of maximum example/activities from the local context

- There should be focus on social and ethical education

\section{Discussion of Results}

Vocabulary given in the textbooks was not according to the standards suggested in the literature for a particular grade and level. Literature suggests two steps down vocabulary from the grade for which the book has been developed for other than language textbooks. Readability level of the textbooks was appropriate to student level but needed further improvement. Most of the approved textbooks are deficient with respect to the characteristics including: a) reflection of ideology of Pakistan in the content; b) durability of cover/binding; c) readability according to student's level; d) alignment of the content with national curriculum objectives; d) connection to diverse student background; e) explanation of the content matter within the student's vocabulary; f) correspondence between size of print and age and grade of students; g) correspondence between style of print and age and grade of students; h) content is helpful in developing thinking skills in the students; i) connection to diverse environment; and k) content matching with student intellectual level.

Majority of the approved books are lacking in the areas including: a) author(s) of the books are known for their mastery in the subject; b) content promotes conservation of environment; c) content is helpful in promoting ideology of Pakistan; d) binding and cover of the books are durable; e) end of chapter assessments are according to student's mental development level; and f) content covers objectives given in the national curriculum. Most of the approved textbooks are aligned vertically and to some extent horizontally within the textbook. However, majority of the approved textbooks are lacking in horizontal alignment with respect to the textbooks approved for the same grade and level. Quality of textbooks with respect to beginning and end material of the chapters or lessons was not considered good by majority of the respondents. Activities explored in the chapter and exercises given at the end of each chapter were also found to be appropriate and suitable.

An explicit criterion for the membership of NTRC was missing at the Ministry of Education. There was no formal pool of reviewers available at the Ministry. There was no setup and/or opportunities available to the textbook writers and evaluators for their capacity building or any orientation in this field. Professional qualification impacted the judgments. The respondents with higher professional qualification gave more balanced and in-depth opinion as compared to respondent with low professional qualification. The same was true for the frequent-users of the textbooks, that is, teachers. Teachers' judgments about the textbooks were more balanced about the different characteristics of a quality textbook as compared to the teacher educators/subject specialists.

Although it was incomplete, the researchers found graded vocabulary of Urdu language for primary classes at Institute of Education and Research, University of the Punjab and the Curriculum Wing of Punjab Textbook Broad. The CW, Ministry of Education did have such kind of resource for the textbook evaluation. CW does have number of textbook evaluators on its panel. Nevertheless there was absence of any explicit criteria for their selection and Standard Operating Procedures to complete the assigned task to them. Furthermore there was no 
common pool of experts regarding vocabulary, assessment, format of textbook, psychologist to settle developmental stages, etc. that could be used for all NTRCs. Majority of the NTRCs did not share their human resources (experts) for the evaluation of textbooks.

In second part of this study, the data collected through two evaluation forms apparently contradicted with majority of the findings in the first part of the study. These include content coverage, meeting the objectives stated in the curriculum outline, print size and style, quality of paper used for textbooks etc. However, through a deeper analysis made by applying various statistical tools, the researchers found that there was an inconsistency in the judgments of the respondents. It might be due to two reasons:

1. The respondents were not professionals in the real sense; rather they were enjoying the status due to the designation assigned to them.

2. The respondents might not have given their judgments after a thorough and in-depth understanding of the processes.

The researchers suggest that the selection of sample for such a study may not be done through obtaining list of proposed respondents; rather it would be better if they could have access to the profiles of the respondents as well. These contradictions between findings in desk review and actual data does not influence the findings of the study as there was an inbuilt process in the study that facilitated the researchers in sharing the findings of the study with the experts who were named in their fields.

The criteria upon which the approved textbooks were evaluated was not very much objective. A lot of inconstancies were found in the approved textbooks. For example, even the contents mentioned in the curriculum document were not fully covered in the textbooks. It was due to lack of objectivity in the review and approval procedure. Absence of explicit procedures for textbook review / evaluation and approval was the major cause for overlooking less/over coverage of contents given in the approved textbooks especially in books developed by the private publisher, as demanded in the National Curriculum. The results point out that merely providing main contents of the curriculum to the authors, do not ensure coverage of the topics demanded in the curriculum. This also reflects upon the working of the evaluators i.e. members of the NTRC. They did not ensure content coverage demanded in the National Curriculum while reviewing and approving the textbooks.

\section{Conclusion and Recommendations}

Textbook evaluation in Pakistan has been subject of debate in the country due to the quality of textbooks approved by the Ministry of Education. Lack of explicit procedures and criteria for textbook evaluation and approval at the ministry were found as major cause for deficiency in the quality of the textbooks. The existing criteria did not actually implement in full scale so as to do ensure the systematic in-depth analysis of the textbooks. It was felt that most of the concerns might be eradicated through pointing out and asking for their modifications. The process of introducing new evaluation criteria needs to be implemented to ensure the quality of textbooks. This is in line with the recommendation made by EDQual [18] that states Improvement in mathematics and science is seen through improving curriculum materials specially the text books.

There is need to develop some documentation that could facilitate textbook evaluation process at the ministry of education that includes: graded vocabulary, role and responsibility evaluators along with their professional development for this particular task. Furthermore, there is need to strengthen the evaluation teams by extending its membership to language and curriculum experts, textbook developers and users (teachers) who could provide input to the evaluation of the textbooks in order to improve the quality. We suggest that similar studies should be done in other subjects and grade levels so as to investigate how far textbook evaluation criteria are appropriate as per perceptions and experiences of teachers and teacher educators involved in the teaching profession. The other stakeholders such as curriculum developers and policy makers in teacher education, and textbook writers may also get benefit of such research studies.

The researchers would recommend that in order to ensure the quality, merely providing main contents of the curriculum to the authors do not ensure coverage of the topics demanded in the curriculum. Textbook quality evaluation criteria should be made them available for use at all stages of the textbook development. There must be mechanism through which the criteria should be shared with them along with the checklist to be certified by the author/s and the publishers that their book is complying to the desired criteria. In order to be able to declare that textbook evaluation is objective, we must be confident that all evaluators have understood the criteria clearly.

It is further recommended that similar studies should be conducted in other subjects and grade 
levels so as to investigate how far textbook evaluation criteria are congruent with the national curriculum as per perceptions of the teachers, teacher educators, and curriculum developers.

\section{References}

[1] Pallo, G., (2006) 'Encyclopedia as Textbook,' Science \& Education, 15, 779-799. (p.779).

[2] UNESCO, (2010) Basic Learning Material Initiative: A guide to sustainable book provision, UNESCO, Paris. (p.12).

[3] Chambliss, J. M. and Calfee, C. R., (1998) 'Textbooks for learning: Nurturing children's minds, Blackwell Publishers, Oxford. (p.7).

[4] Heyneman, S., Farrell, J., and Sepulveda-Stuardo, M., (1978), 'Textbooks and Achievement: What we know' (World Bank Staff Working Paper No. 289). Washington, DC: World Bank. Cited in Jeannie Oakes and Marisa Saunders (2004), 'Education's most basic tools: Access to textbooks and instructional materials in California's public schools', Teachers College Record, 106 (10), 1967-1988.

[5] Siddiqui, S., (2007) 'Rethinking Education in Pakistan: Perceptions, Practices, and Possibilities', Karachi: Paramount Publishing Enterprise. (p.103)

[6] Tasneem, F. (2008) 'Exploration of post-colonial English curriculum: an investigation of an under graduate English textbook in Pakistani University', Unpublished Master's Thesis, Faculty of Education, York University, Toronto, Ontario.

[7] Quraishi O. R., (2004, June 6) 'Textbook questions', The Dawn, p.5.

[8] SDPI Research \& News (2005, August-December), Salim, 'A Review of the Textbooks', 12(4), p.5.

[9] Jafarey, N. A. (2005, June 20) 'Why Pakistan lags behind in research', The Dawn, p.5.

[10] Khan, L. A., (2006) 'Pakistan and modern world', In S. Shaikh (Ed.), A selection of modern English essays, The Caravan Book House, Lahore.

[11] Pingel, F., (2010) 'UNESCO guidebook on textbook research revision (2nd ed.)'UNESCO; Braunchweig: George Eckert Institute for International Textbook Research, Paris.

[12] Vogat, W. P. (2005). 'Dictionary of Statistics and methodology’ (3rd ed.), Saga Publication Inc. London.

[13] Fraenkel, J. R. \& Wallen, N. E., (2006) 'How to design and evaluate research in Education' (6th Ed.) McGraw Hill, New York.
[14] Riazi, A. M., and Mosallanejad, N., (2010) 'Evaluation of Learning Objectives in Iranian High-school and Pre-university English Textbooks Using Bloom's Taxonomy', TESL EJ, 13(4), 1-16.

[15] Scott, J. A. and Nagy, W.E., (2003) 'Developing word consciousness' J. Baumann and E. Kame’enui (Eds.) 'Vocabulary Instruction: Research to Practice, Guilford Publications, New York.

[16] Ebbers, S. M., (2004), 'Vocabulary through morphemes: Suffixes, prefixes and roots for intermediate grade', Sopris West, Longmont.

[17] Sedita, J., (2005) 'Effective Vocabulary Instruction', Insights on Learning Disabilities, 2(1) 33-45.

[18] EDQual, (2007) 'Programme consortium on implementing Education quality in low income countries' (midterm review: Implementing curriculum change project literature reviews Pakistan, South Africa and Rwanda). Available at http://www.dfid.gov.uk/R4D/PDF/Outputs/ImpQuality_RP C/icclitreview.pdf. 